\title{
Commentary: Just passing through
}

\section{Keith B. Allen, MD, and Graham Pollock, MD}

Larson and colleagues ${ }^{1}$ in their article "Fat Embolism in Transit: Report of a Rare Phenomenon" illustrate how the increased use of total body computed tomographic scans by the trauma service can reveal interesting and lifethreatening problems that can be mitigated by a thoughtful cardiac surgeon. Fat embolism following traumatic fractures of long bones or the pelvis is probably a more frequent occurrence then realized but rarely does it lead to fat embolism syndrome; even rarer is it captured and illustrated as well as in this unique case. The thought process for managing this case with a full sternotomy and cardiopulmonary bypass was guided by the size of mass, presence of a patent foramen ovale with concern for embolization, the possibility for malignancy, and finally the rarity of the problem. Although several different surgical options could be

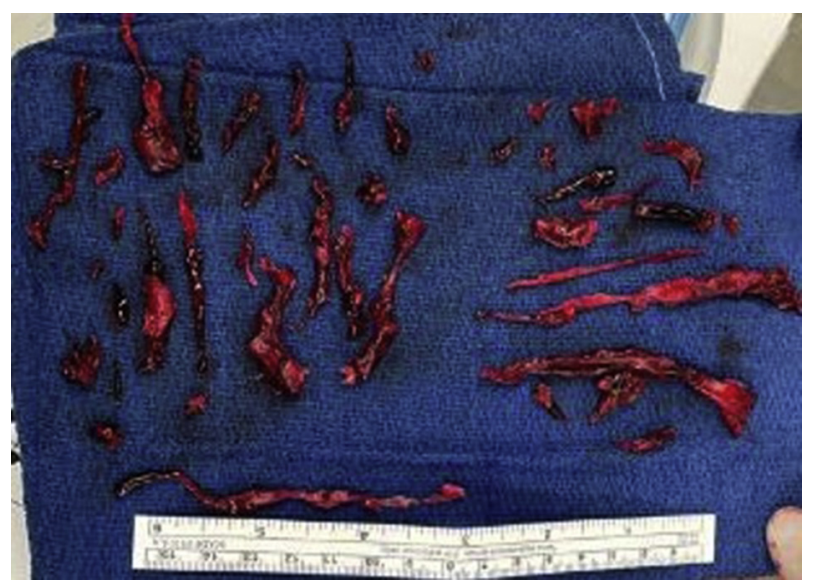

FIGURE 1. Emboli in transit removed percutaneously with aspiration device in a patient with $\mathrm{PFO}$.

From the Saint Luke's Mid America Heart Institute and University of MissouriKansas, City School of Medicine, Kansas City, Mo.

Disclosures: The authors reported no conflicts of interest.

The Journal policy requires editors and reviewers to disclose conflicts of interest and to decline handling or reviewing manuscripts for which they may have a conflict of interest. The editors and reviewers of this article have no conflicts of interest.

Received for publication June 30, 2021; revisions received June 30, 2021; accepted for publication July 1, 2021; available ahead of print July 6, 2021.

Address for reprints: Keith B. Allen, MD, 4320 Wornall Rd, Medical Plaza II, Suite 50, Kansas City, MO 64111 (E-mail: kallen2340@aol.com).

JTCVS Techniques 2021;9:100

2666-2507

Copyright (C) 2021 The Author(s). Published by Elsevier Inc. on behalf of The American Association for Thoracic Surgery. This is an open access article under the CC BY-NC-ND license (http://creativecommons.org/licenses/by-nc-nd/4.0/).

https://doi.org/10.1016/j.xjtc.2021.07.001

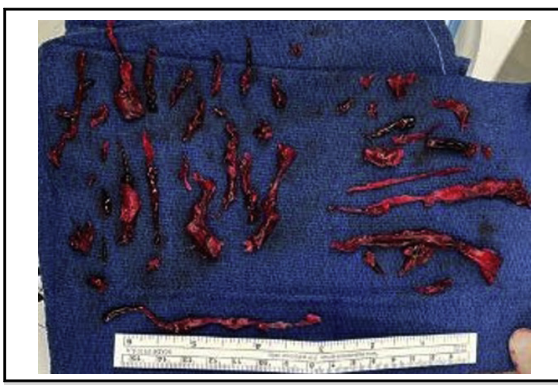

Emboli in transit removed percutaneously with aspiration device in a patient with PFO.

CENTRAL MESSAGE

Passing through the heart; fat embolism in transit.

envisioned, Monday-morning quarterbacks who argue that a percutaneous or less-invasive approach might have achieved the same result live comfortably with hindsight on their shoulder and weren't there in the moment. Cardiac surgeons should, however, become familiar with the various percutaneous aspiration technologies, which in the future could turn hindsight into foresight. Management of "clot" in transit and large pulmonary embolisms, while certainly different pathology then present in this case, are increasingly being managed percutaneously with and without cardiopulmonary assist (Figure 1). Successful outcomes should always be commended regardless of the road taken; however, some roads are easier traveled, particularly for the patient.

\section{Reference}

1. Larson EE, Moe DM, Craig JC, Hoffman JRH. Fat embolism in transit: report of a rare phenomenon. J Thorac Cardiovasc Surg Tech. 2021;9:97-9. 